\title{
Visualization of the Processes of Performance Management and Evaluation of the Personnel Potential of the University
}

\author{
V.D. Kolychev ${ }^{1}$, N.A. Budanov² \\ National Research Nuclear University «MEPHI», Moscow \\ 1 ORCID: 0ooo-0oo2-8616-9354, kolychev@mephi.ru \\ 2 ORCID: oooo-0002-9714-2915, nabudanov@mephi.ru
}

\begin{abstract}
The article is devoted to the development and application of a set of visual analytical models used in performance management based on key indicators and the assessment of the University's human resources potential using integrated information and analytical tools. The relevance of the development and application of visual analytics methods is aimed at improving the efficiency of management decision-making, strategic planning and assessment of the potential for growth and development. The need to develop methods of visual analytics in the field of performance management is due to the current reconfiguration of the functioning of large-scale competitive high-tech enterprises, focused primarily on improved goal-setting technology and the use of modern methods of analyzing human resources. The article presents a set of visual models used for a comprehensive analysis and evaluation of the effectiveness of the organization, based on the use of a set of geometric modeling tools that allow you to use modern computer tools to demonstrate methods of making managerial decisions. The set of visual models proposed by the authors provides researchers with the opportunity for visual geometric interpretation and identification of existing dependencies that arise when solving applied problems by means of visual analytics, which often, in addition to the geometric solution method, do not have alternative approaches for creating effective algorithmic methods.

Keywords: Key performance indicators, target management, personnel potential, performance management, engagement, horizontal interaction, individual development plan, personnel reserve, self-assessment.
\end{abstract}

\section{Introduction}

In many cases visual analytics methods are the only instrument for developing an algorithmic method for solving weakly formalized or low formalized tasks in the field of data processing, analyzing numerical sequences, working with fuzzy sets and linguistic variables. In the field of performance management processes, a number of visual approaches are also emerging, focused primarily on the use of modern visual analytics tools in order to conduct a comprehensive study in the field of organizational development.

The article presents a visual approach to solving the problems of decision-making in the field of managing the processes of efficiency of activity and the development of the personnel potential of an educational organization.

Attention is paid to the development and application of visual methods based on the use of software and information support tools for the activities of a modern educational institution as a high-tech corporation that solves the problems of change management, improving competitiveness, managing high-tech projects and programs, developing and promoting promising products and services both in the field of educational and research activities. 
The technology of forming maps of key performance indicators, the development of human resources as one of the main tools for the development of the University is becoming increasingly popular in the educational environment, which is increasingly focused on digitalization and the realization of competitive advantages in educational and research activities.

Using the software tool package of applied business analytics programs KPI Monitor Analyzer, a set of management decision - making tasks is solved and a set of interrelated visual models is built that form a system picture of the functioning and development of an educational organization based on key performance indicators-a modern digital University focused on the transformation of the scientific and educational agenda, striving to occupy a promising sector of the economy.

\section{Visual model of the cyclical process of strategic target management}

The processes of performance management in the organization are aimed at implementing a model of sustainable development in accordance with the developed system of key strategic goals and indicators. Procedures and methods of instrumental support of the organization's activities and management decision-making are built significantly on the basis of a set of visual models [1] that contribute to the formation of the geometric appearance of the controlled object $[2,3]$, the display of its parameters and reflection of geometric characteristics that are significant from the of management point of view [4]. Schematically, the process of goal-based management, which implies the interaction of elements (stages) and the impact on performance indicators that measure the degree of development through the decomposition of goals, planning and implementation of measures is presented in Figure 1.

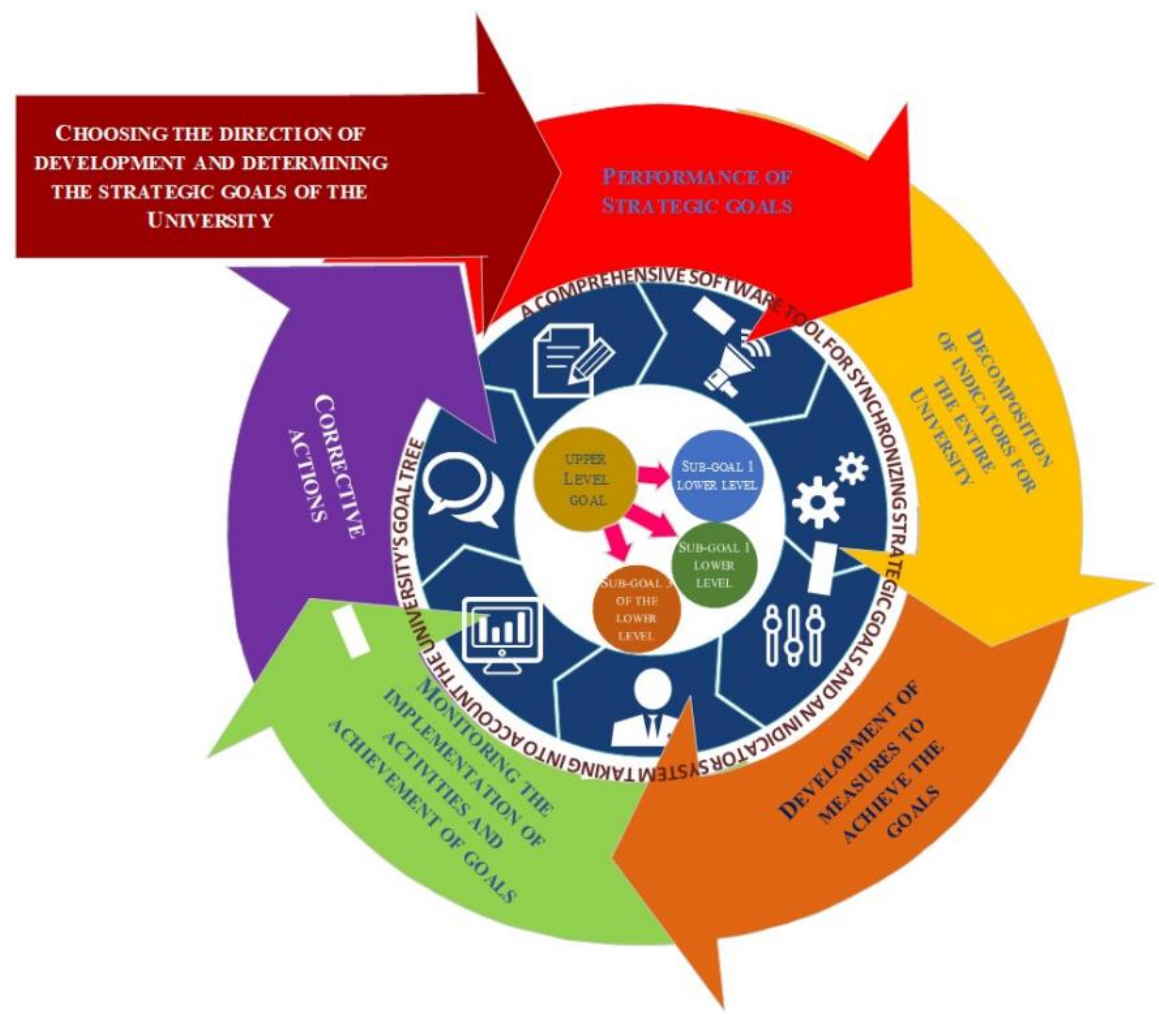

Fig. 1. Visual system model of the cyclical process of strategic management by goals

The process of strategic target management consists of a set of related stages, including the choice of development vectors, the positioning of strategic goals, the decomposition of the compiled system of strategic goals into organizational units, the development of measures 
aimed at achieving the set goals, the implementation of control and the development of corrective measures. Within the framework of the model of the cyclical process of strategic management by goals, it is necessary to maintain the availability of software tools [5] that synchronize the strategic goals of the organization, plans and monitoring of their implementation, taking into consideration the formation of goals tree. It is possible to visualize the distribution of responsibility for the hierarchical relationship of indicators and to ensure the comparison and decomposition of the created system of indicators on the maps of employees' key performance indicators [6], using a visual geometric interpretation of planning processes.

As can be seen from Figure 1, the fundamental stage is the definition of a system of indicators aimed at achieving the strategic goals of the University's development in the short and medium term.

As a rule, the system of strategic indicators of an organization exists in the format of a goal tree, in which goals and indicators are linked to each other in accordance with the principle of decomposition. A visual model of the University's goals tree is shown in Figure 2.

The expediency of using the hierarchical principle of visual planning is aimed at identification of priority areas that affect the development of the University. In this case, the goal tree acts as a tool for correlating goals and key performance indicators, forming a realistic picture of the economical content of the University's activities, identifying areas and directions of development of an educational organization, developing a list of performers responsible for achieving the intended goals. In general, the visual model of the goal tree corresponds to the structure of the University's management system, implementing a unified logical model of the organization's formation based on systematical principles, displaying relations between indicators, taking into consideration drivers and indicators for the organization of monitoring activities.

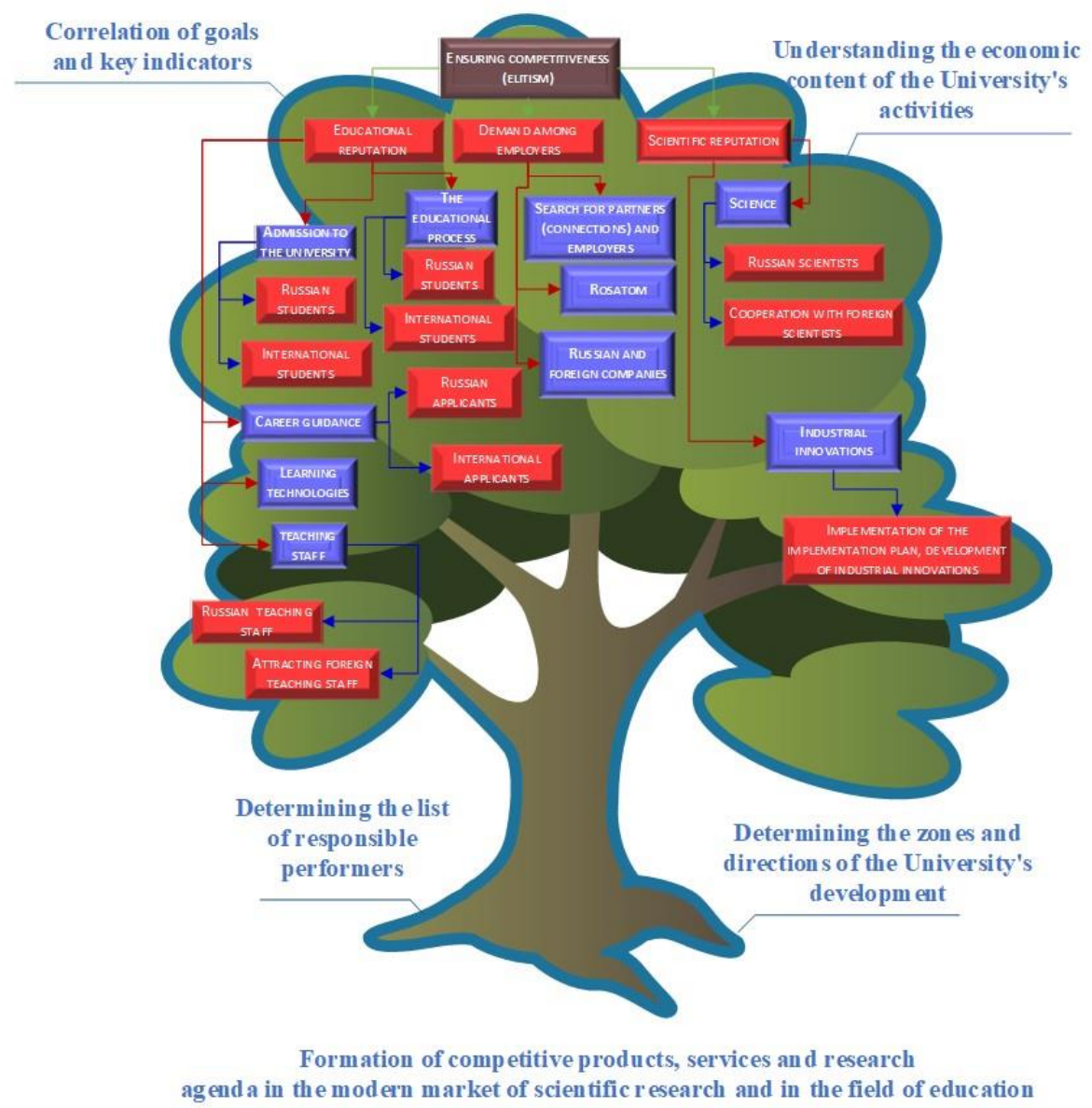

Fig. 2. Geometric model of the University's goals tree, reflecting the principles of decomposition of strategic performance indicators 


\section{Process architecture and software implementation of visual models for evaluating the effectiveness of activities and evaluating human resources}

Creating a unified systematic model of the process of evaluating the effectiveness of activities and human potential, it is necessary to provide the researcher with a comprehensive analysis tool that can reveal the interrelationships of processes and detect the characteristics of the object under study that are significant from the management point of view.

Figure 3 describes a complex model of the process of evaluating the effectiveness of activities and assessment of the personnel potential of the organization's employees, implemented using the KPI Monitor Analyzer software tool, displaying a list of stages included in the integrated analysis of the university's activities.

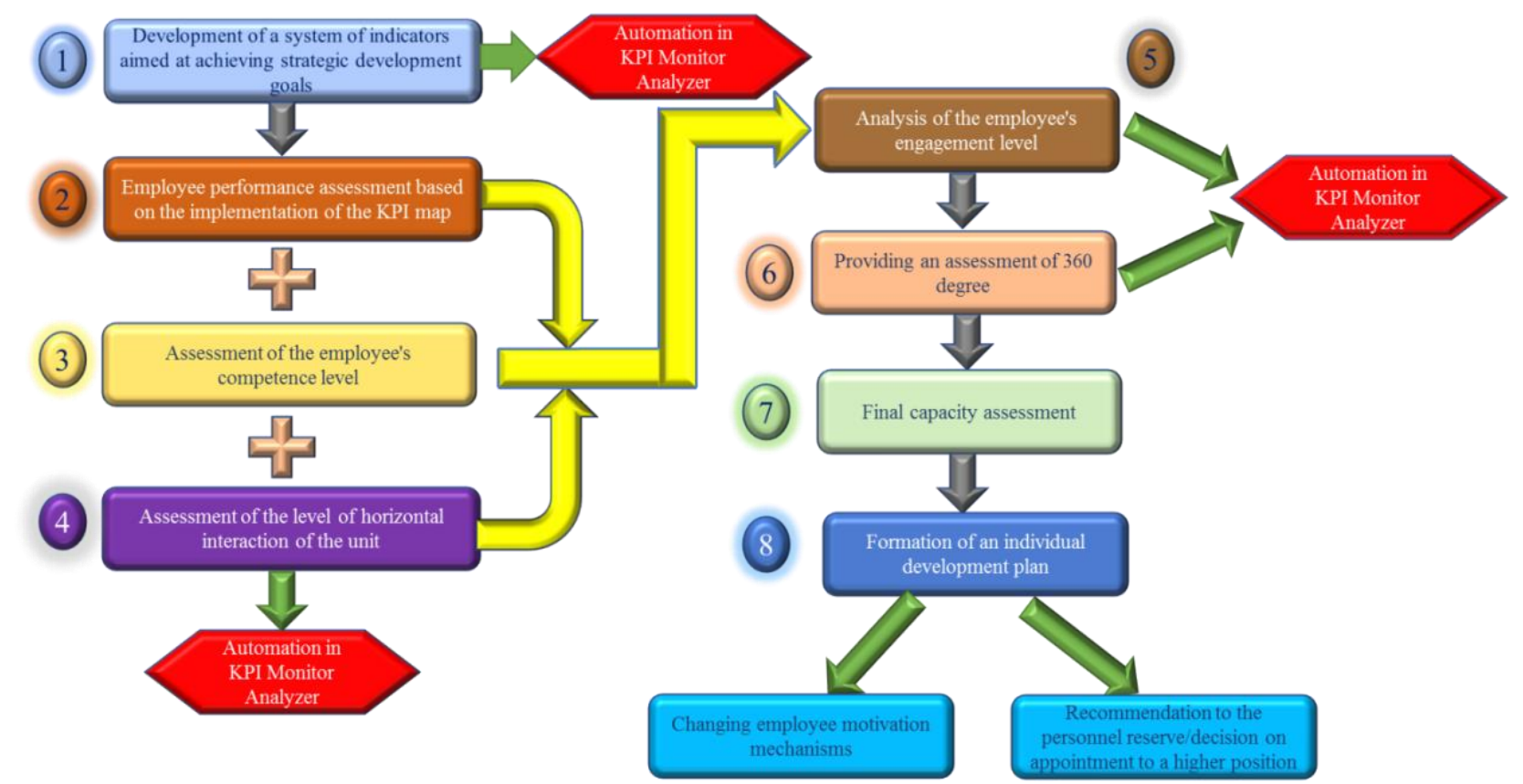

Fig. 3. Visual model of the process of evaluating the effectiveness of activities and evaluating the personnel potential of employees

The sequence of the stages shown in Figure 3 allows to provide comprehensive in-depth instrumental analysis of the organizational development of the University using visual models used by a researcher or a group of analysts.

Each selected stage corresponds to a specially developed visual analytics model that allows researcher to provide both qualitative and quantitative interpretation of the results obtained in the process of analyzing the effectiveness of activities.

During development of strategic performance indicators system, a visual model is used in the format of an oriented graph, at the vertices of which strategic areas of activity related to functional zones and functional divisions responsible for their implementation are located.

The relationship between the set of strategic performance indicators and functional areas of activity at the University is shown in Figure 4. The influence of the functional area of activity on the strategic performance indicator is indicated using a system of pointers that visually displays the contribution to the indicator. For example, as shown in Figure 4, the functional direction of mass communications affects the development of the academic reputation of the University, the reputation of the university among employers, the share of foreign students in the total number of students. 


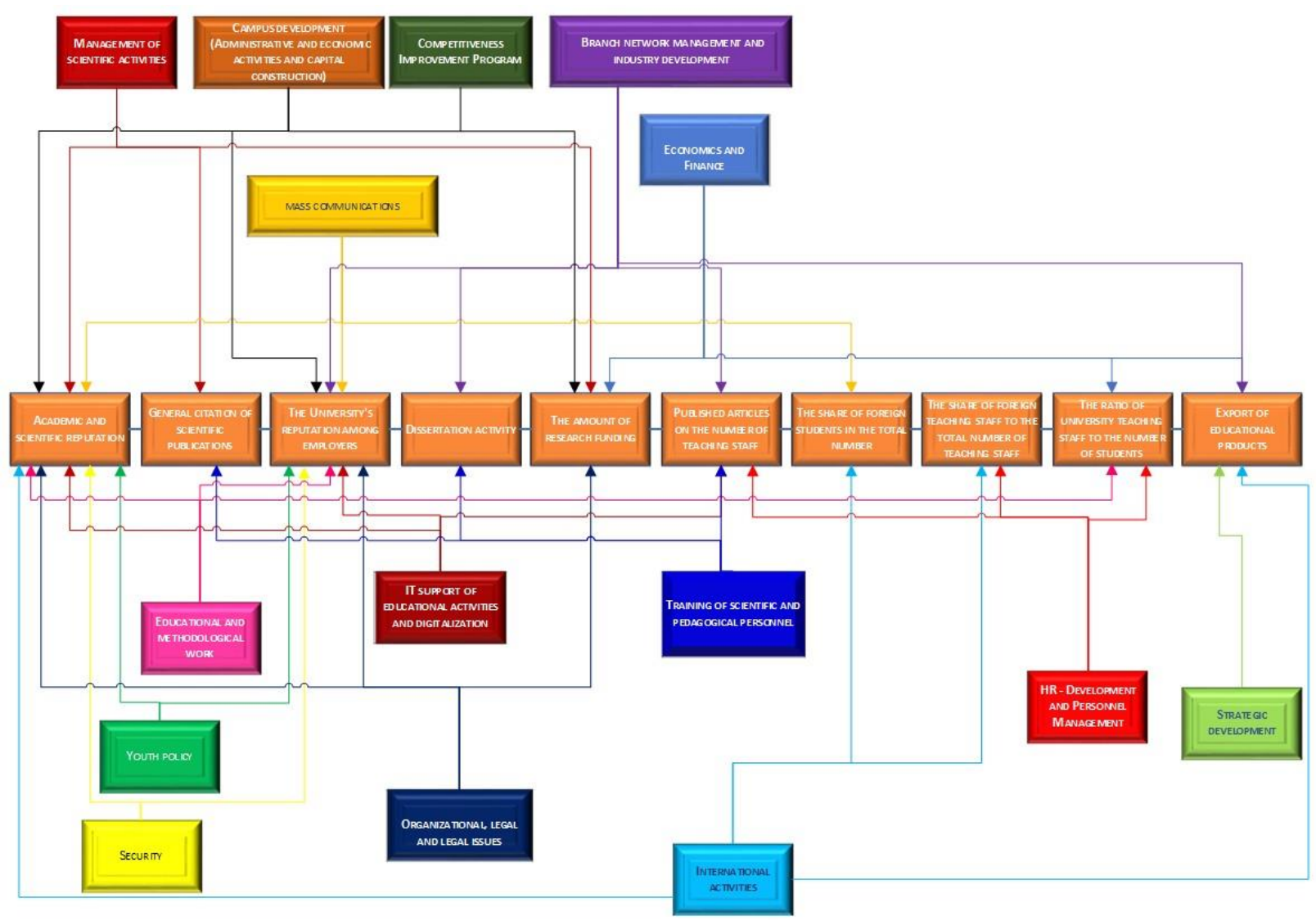

Fig. 4. Visual model of the influence of functional directions on the system of strategic indicators of the University

The KPI Monitor Analyzer analytical system is a business analytics application $[5,13,14,16]$, implementing the functions of modeling and managing a balanced scorecard system that supports targeted management, implementing the processes of personnel evaluation and motivation, having powerful software visualization tools and displaying a dynamic system of University development indicators.

The functionality of the software product includes data collection and processing, providing flexible means of integration with the organization's information systems, consolidation of classifiers and reference books, multidimensional and multilevel analysis, processing of large amounts of information, reporting in a corporate style using a built-in graphical library, parametric adjustment of indicators.

Visual data analysis provided by KPI Monitor Analyzer includes a system of visual user desktops with indicators assigned to responsible performers, providing the availability of visual monitoring of the achieved level of the value of each indicator, taking into consideration historical retrospectives. Figure 3 shows the functional tools implemented using the KPI Monitor Analyzer system, involved in the research provided at the NRNU MEPhI University.

Figure 5 represents the general scheme of adaptation and justification of the KPI Monitor Analyzer software tool, implemented as part of project-oriented solutions for implementing the process of performance management and personnel potential assessment in the University context. 


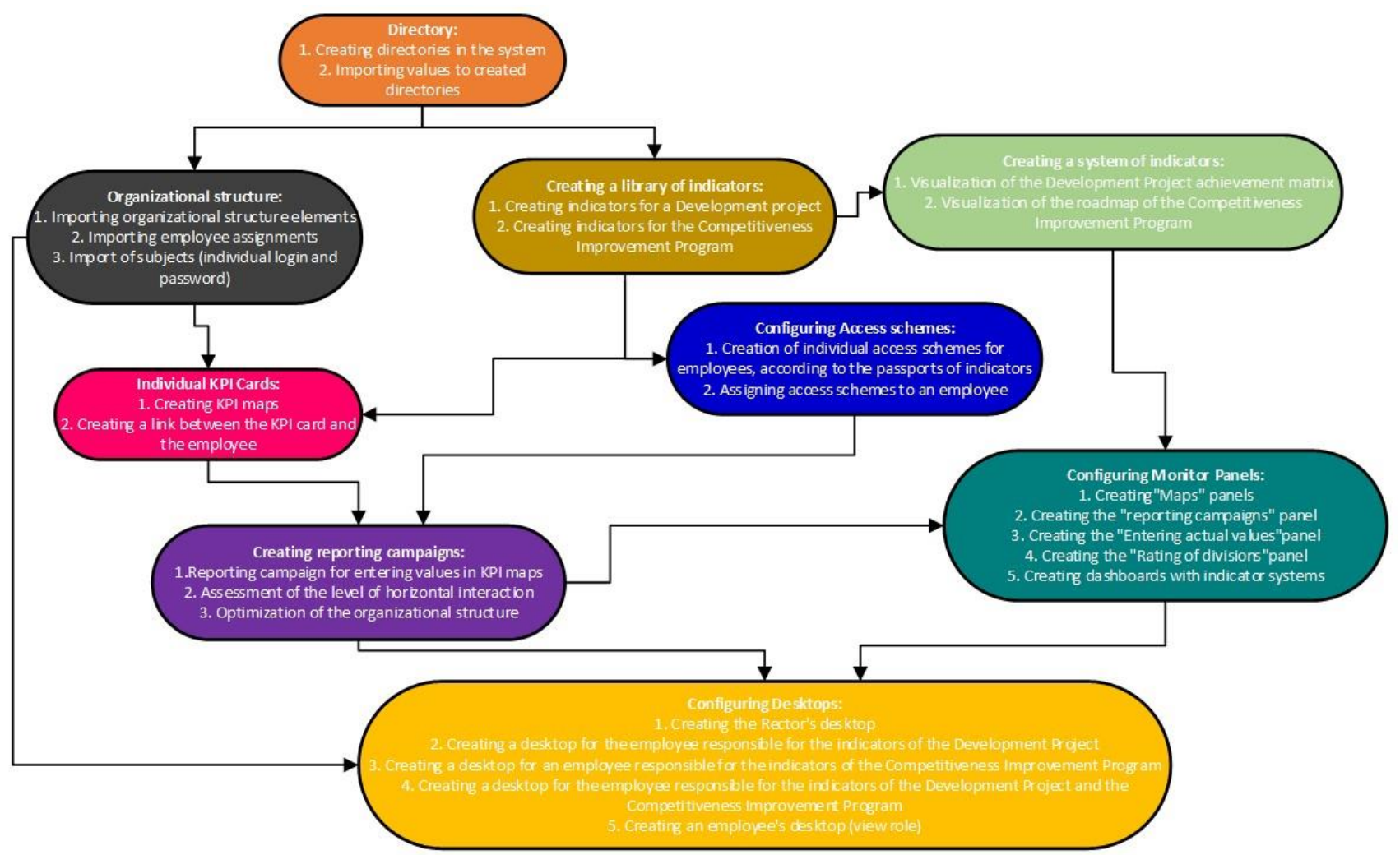

Fig. 5. Visual model of parametric configuration and adaptation of the KPI Monitor Analyzer software product at the University

The formation of a visual model of management and decision-making using a geometric representation of the system of strategic indicators in an educational organization is implemented using a set of objects displayed in the format of a related oriented graph representing the dependencies between indicators. At the nodes of the graph of the indicator system, there is a display of the achieved level of the value of performance indicators, as well as a color indication that initiates attracting additional attention to the indicator highlighted in red or yellow.

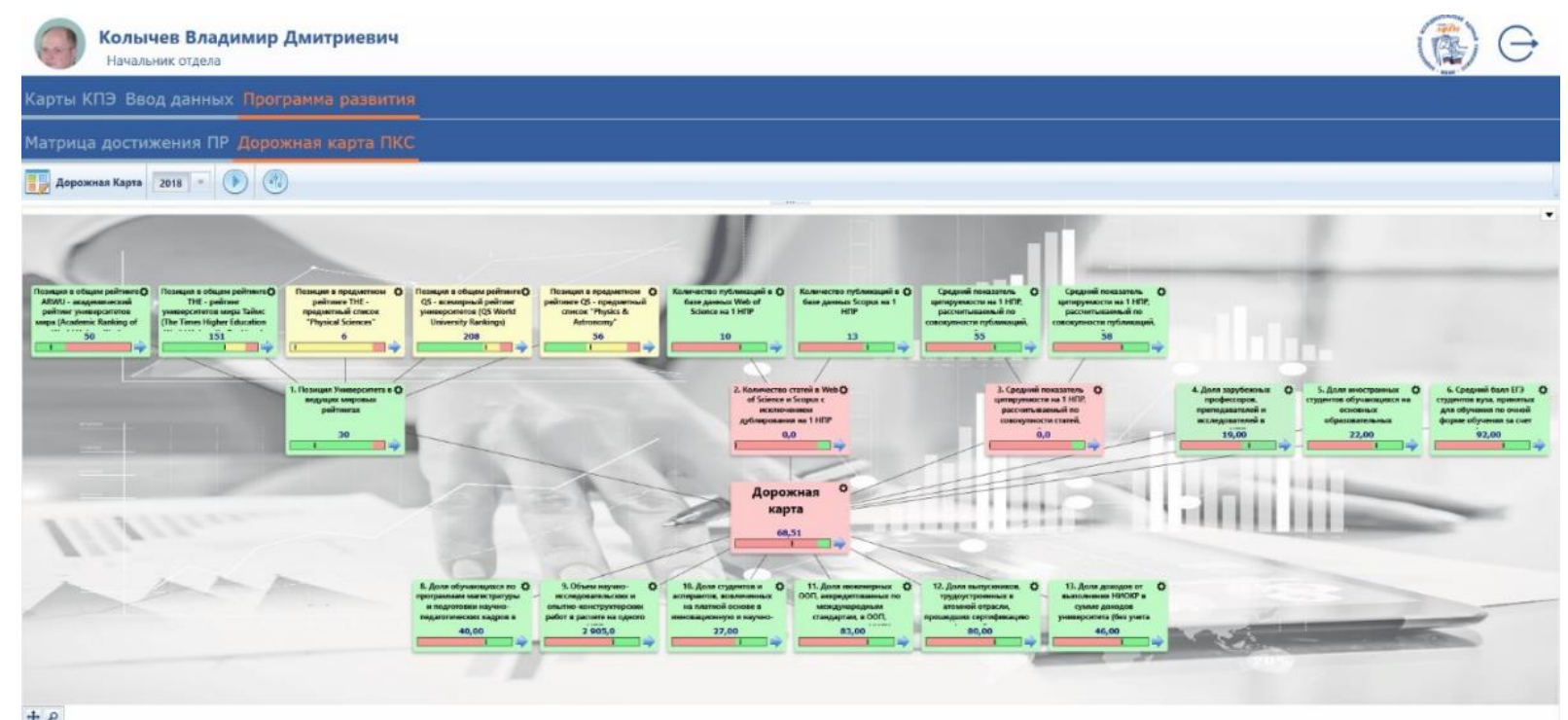

Fig.6. Visual model of the roadmap for the development of the university in the format of an oriented graph, in the vertices of which there are performance indicators 
In the format of a visual model, a complex action can be presented, focused on achieving the values of indicators pre-given in the controlled period. Figure 7. represents a visual model of a comprehensive university development program over an annual period of time.

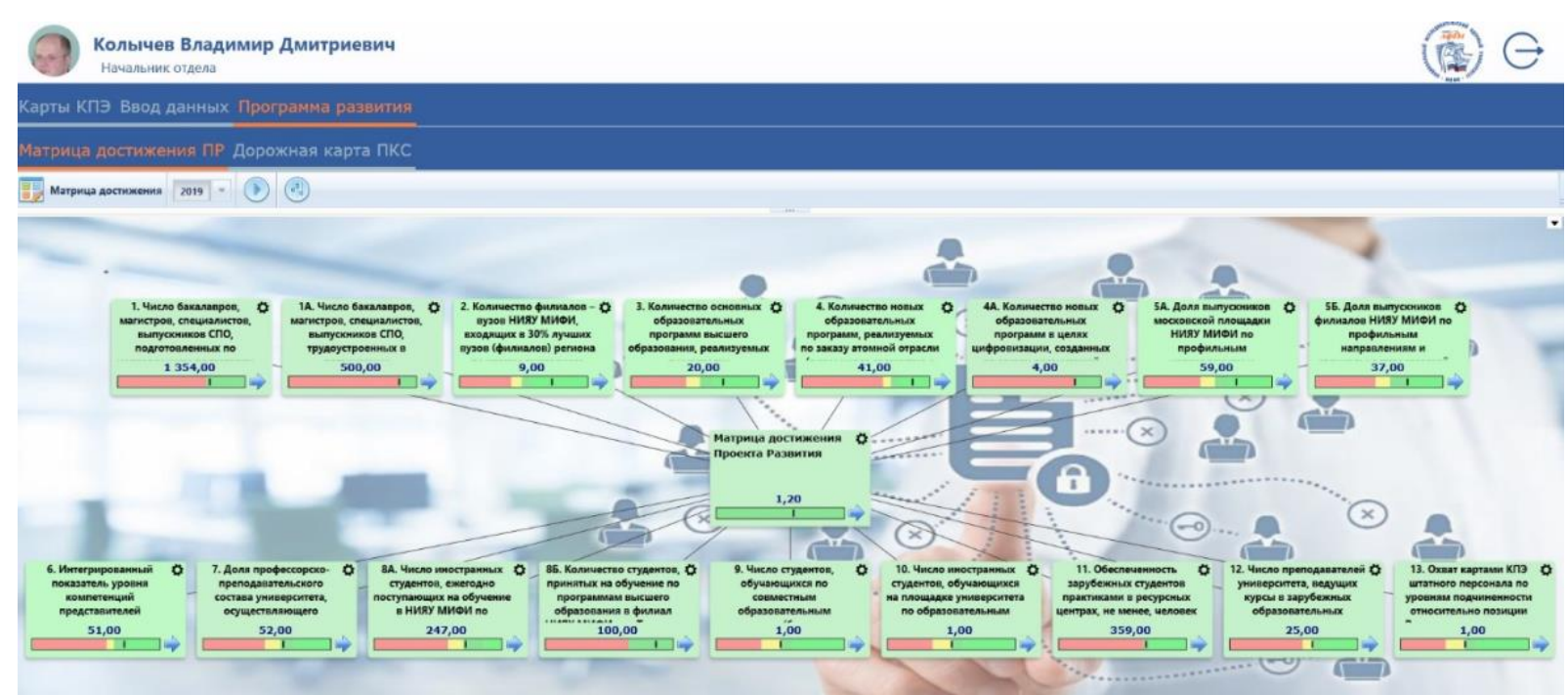

Fig 7. A visual model of a comprehensive development project in the university in format of an oriented graph with an indication of the values of indicators

Modeling of the dynamics of changes in the selected efficiency indicator can be performed using the KPI Monitor Analyzer tool software. Figure 8 represents an analytical visual representation of the dynamics of changes in the indicator reflecting the number of security documents in the field of intellectual property received by the services and research scientific units of the University.

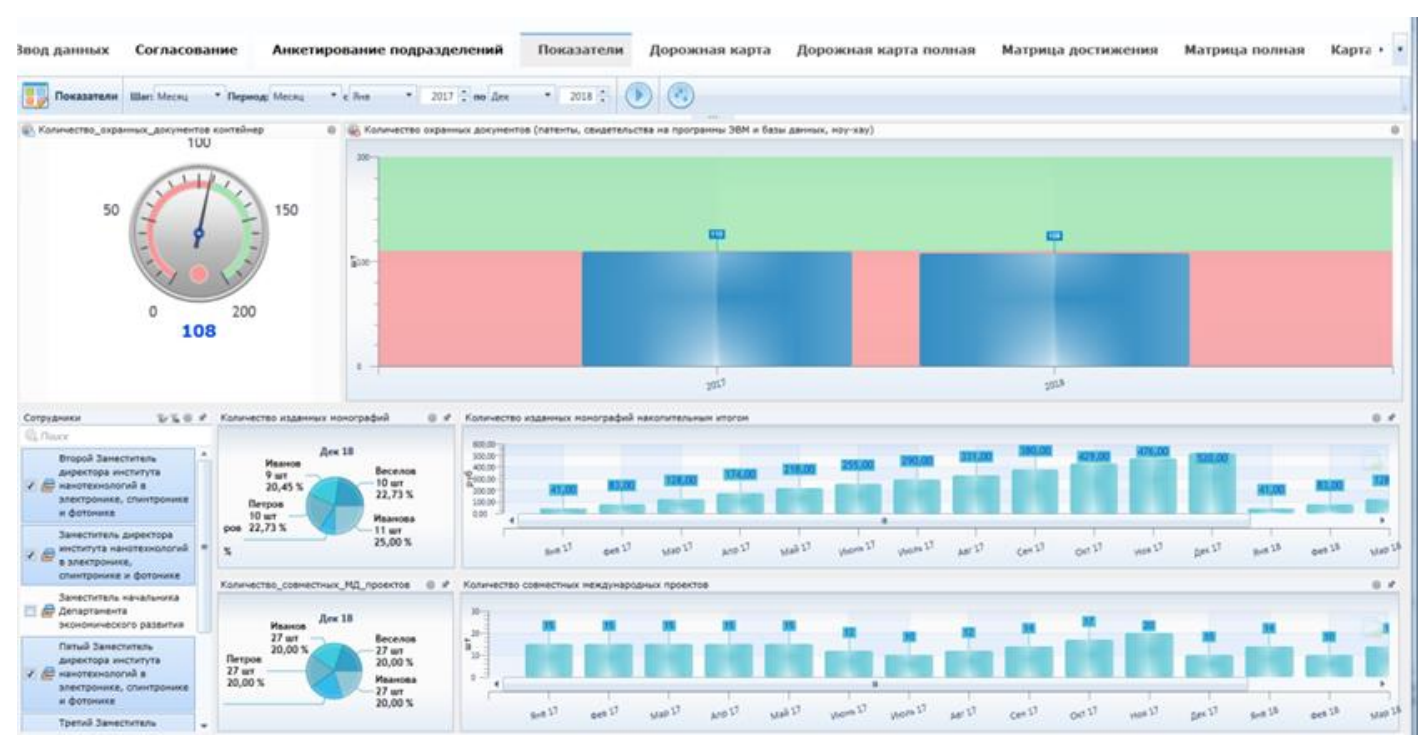

Fig 8. Visual model of the dynamics of changes in the indicator included in the developed system

Revealing the process of evaluating of the activities effectiveness, it is possible to proceed to the formation of a key performance indicators (KPIs) map of managers ' productivity. General strategic indicators from the goals tree are transferred to the performance indicator map of the manager responsible for achieving the set indicator value, thus forming a strategic block of indicators with a total weight of $20 \%$. The KPI map model also contains blocks of the functional direction of activity and the results of the employee's assessment by the direct 
supervisor. Functional performance indicators in the KPI map have a group weight of $60 \%$, and the manager's assessment acquires a weight of $20 \%$.
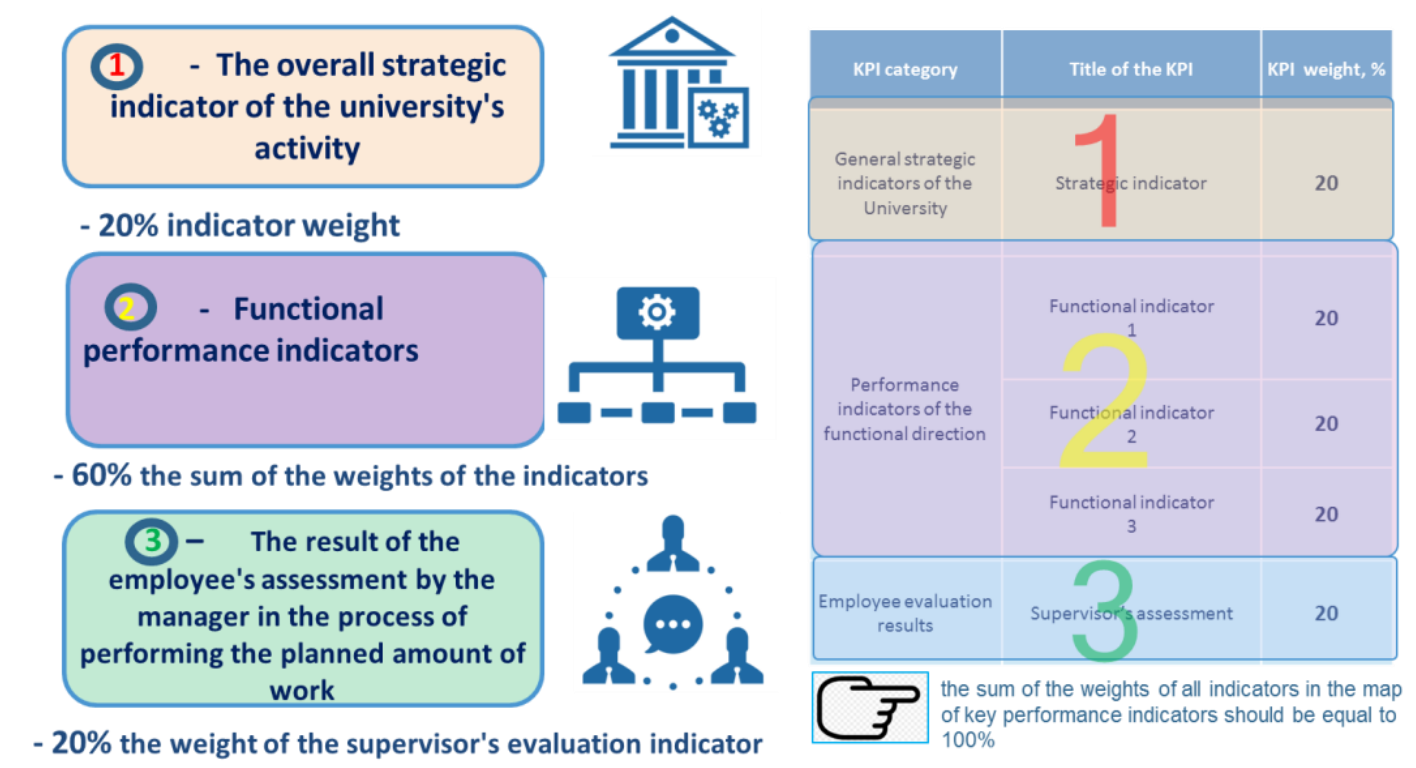

Fig 9. Visual model of the map of key performance indicators of the University' manager

Figure 10 represents a visual model of the manager's KPI map, implemented using the KPI Monitor Analyzer tool in the user's desktop format.

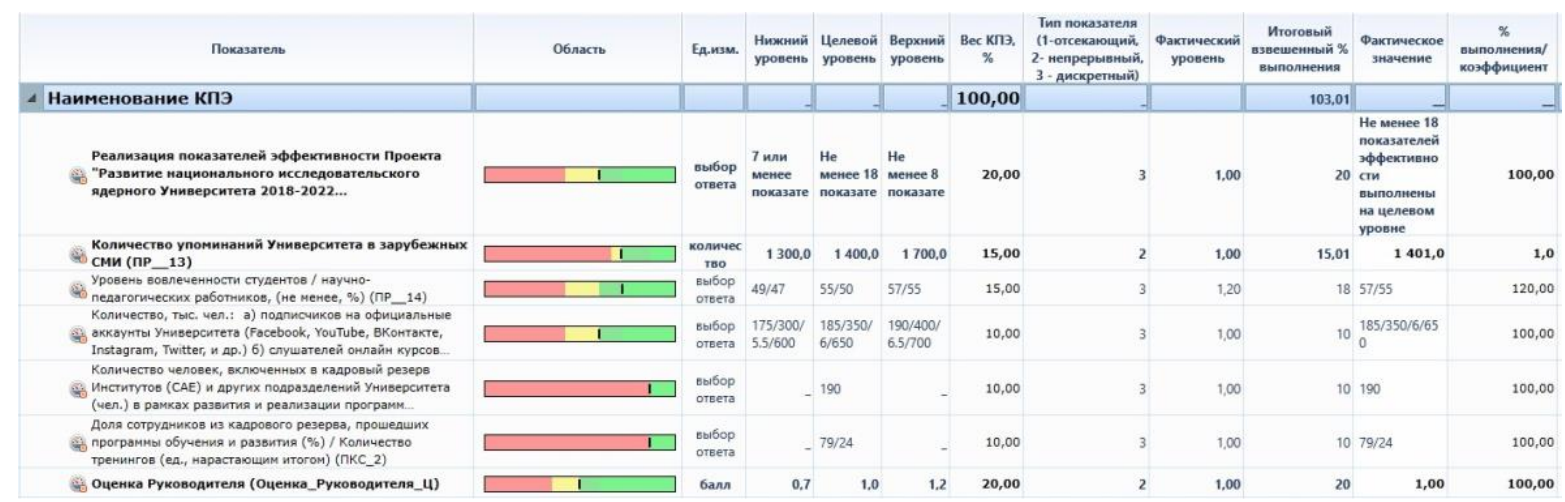

Fig 10. A visual model of the manager's KPI map, implemented using the KPI Monitor Analyzer software tool

The assessment of the horizontal interaction level between departments and divisional units is carried out by providing an online survey system based on the application of the university's corporate portal or a specialized software tool. The purpose of implementing a system for assessing the level of horizontal interaction is to reduce the share of inefficiently working departments. Figure 11 shows a visual representation of the process of implementing a system for assessing the level of horizontal interaction between departments. 


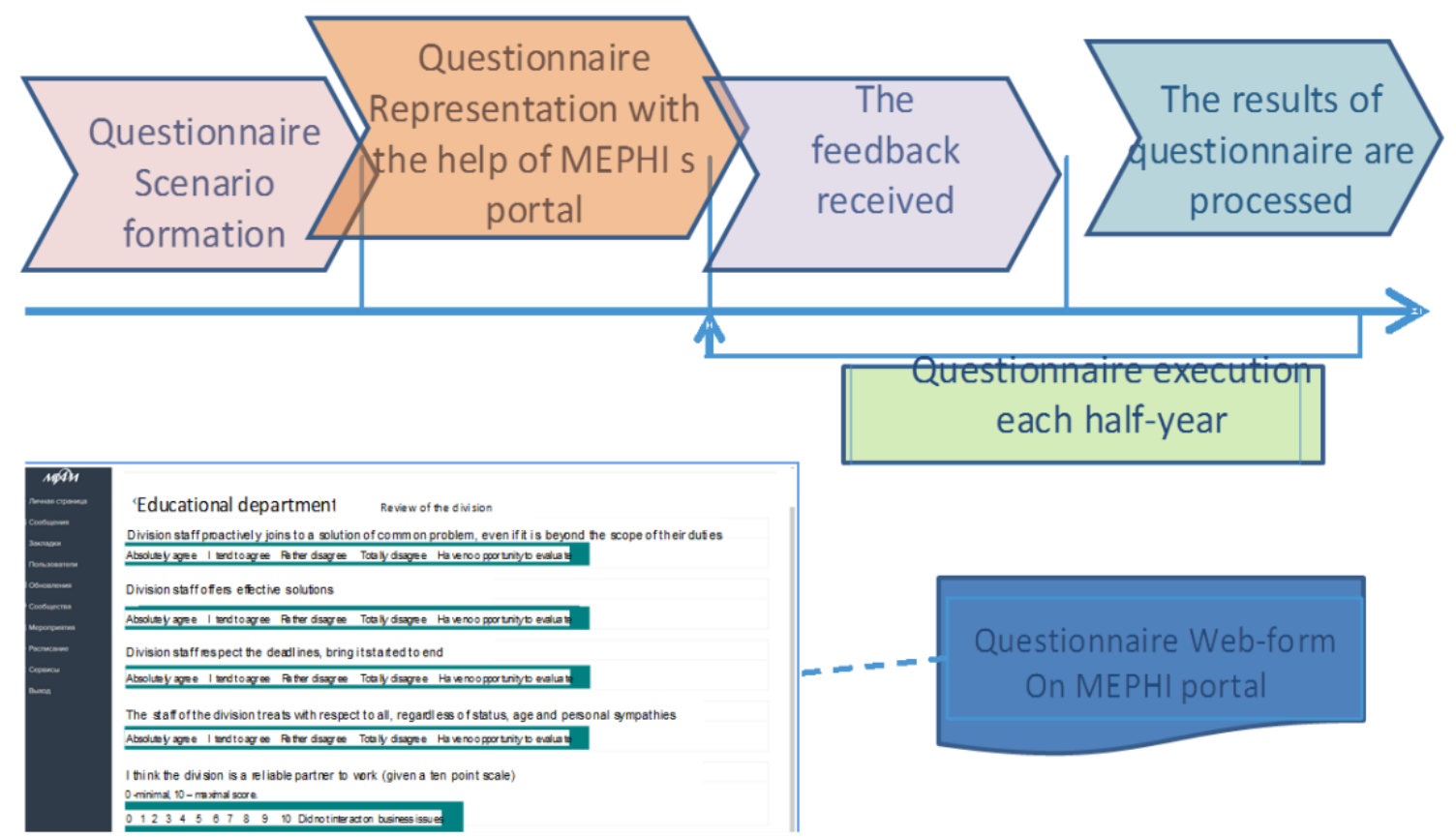

Fig 11. Visual representation of the process of implementing a system for assessing the level of horizontal interaction of departments

The questionnaire developed in the KPI Monitor Analyzer system for providing a study of the level of horizontal interaction between departments is represented in Figure 12.
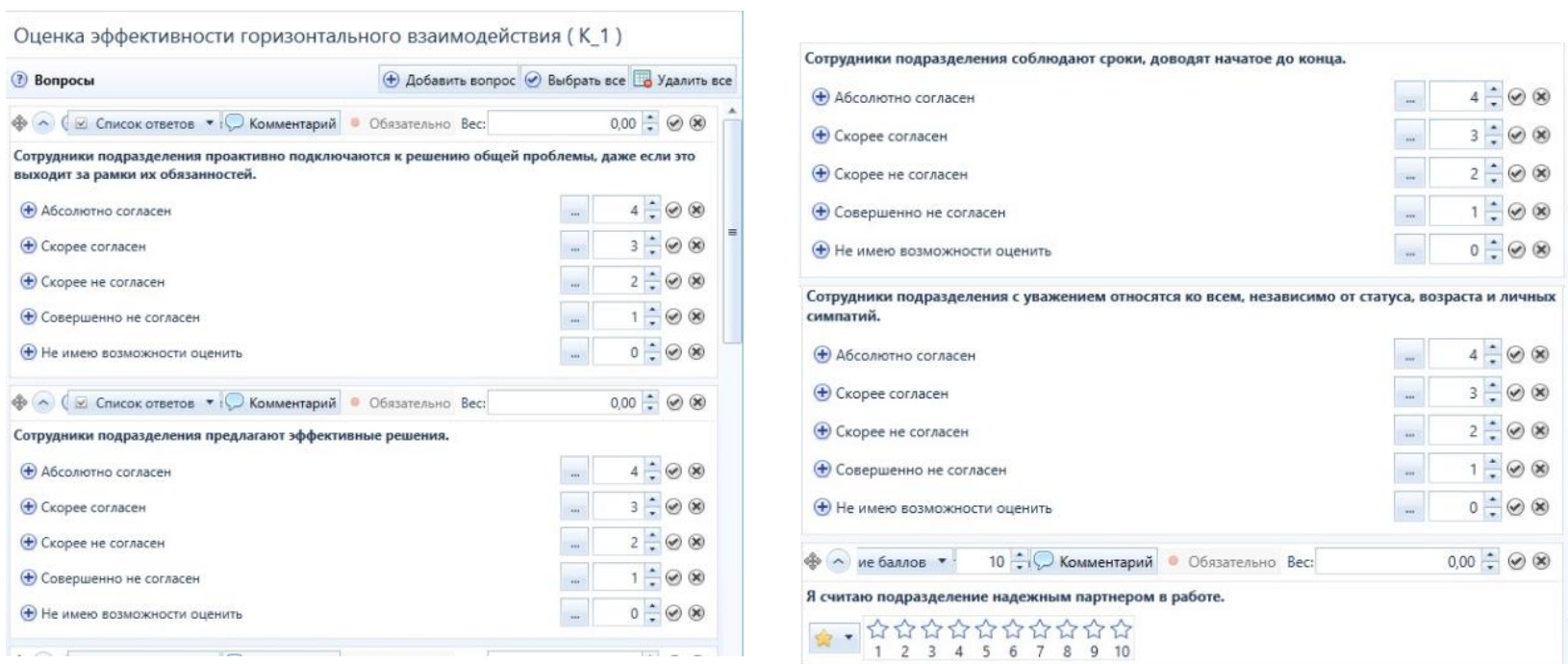

Fig 12. Visual adjustment of the questionnaire for evaluating the effectiveness of horizontal interaction

The form of visual representation of the results of the study of evaluating the effectiveness of horizontal interaction is represented in Figure 13. 

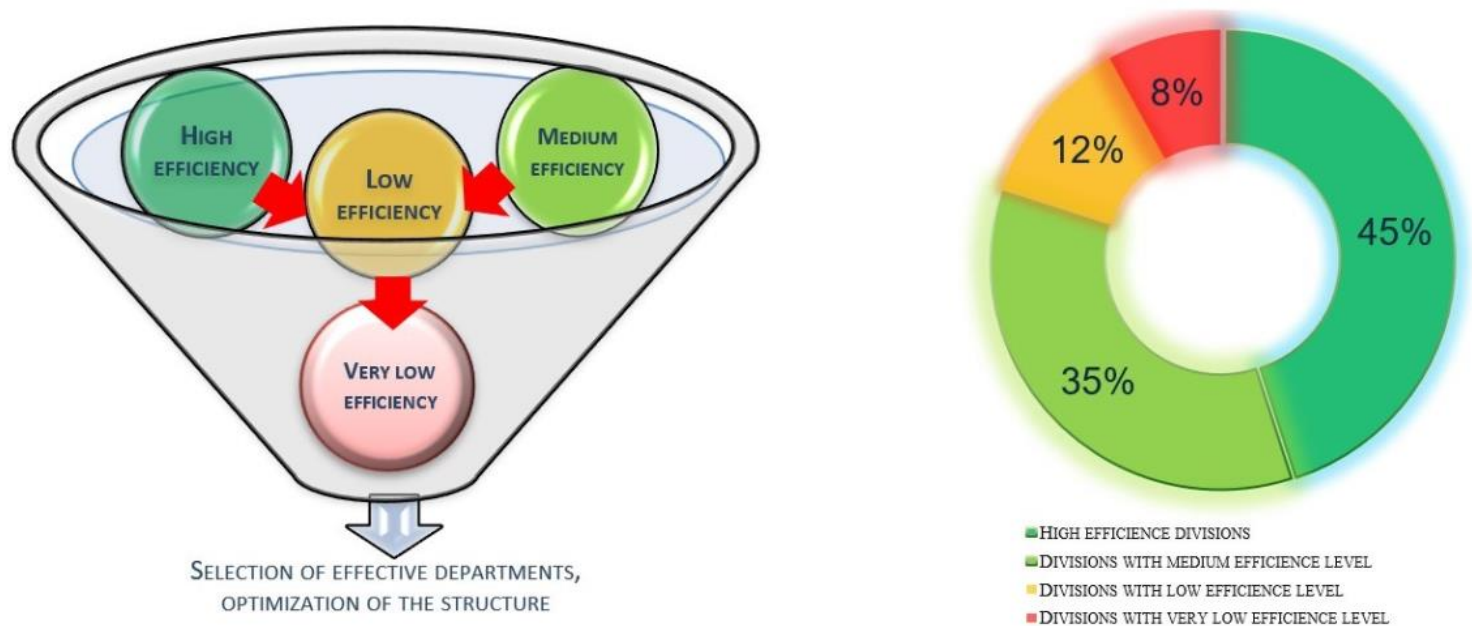

Fig 13. The results of the visual distribution of divisions into efficiency groups for the purpose of further making optimization decisions

The assessment and analysis of the parameters of the organization employees' engagement is carried out with the help of a specialized investigation, which is usually implemented using specialized information tools for providing the surveys [9].

The concept of engagement contains a number of factors that determine the psychoemotional state of employees, analyzing the balance of work, study and personal life, Figure 14 presents a visual model of the parameters of engagement $[9,10]$.

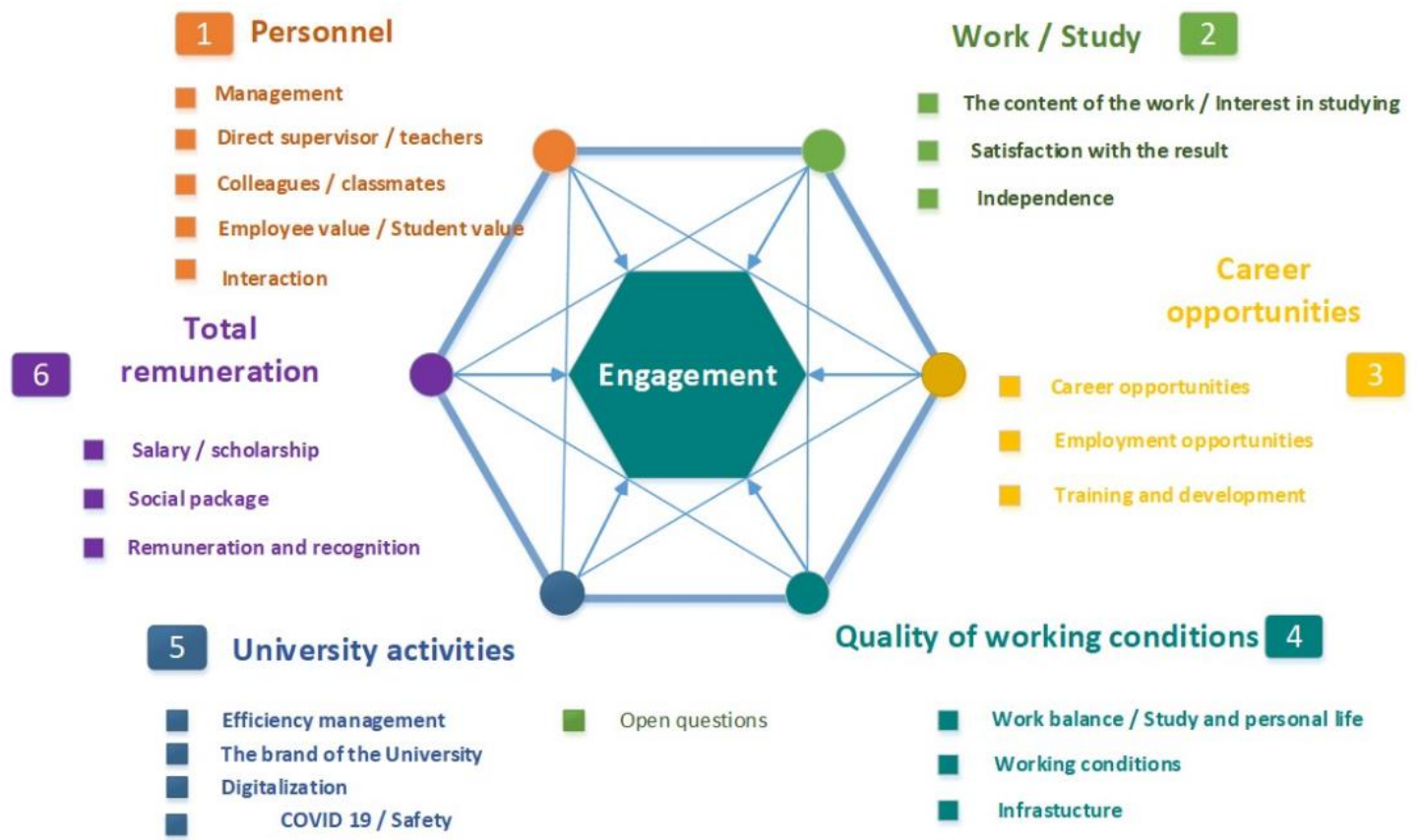

Fig 14. Visual model of the parameters of analysis and measurement of the indicator of engagement of students and research and teaching staff of the University

During the questionnaire constructing taking into consideration the above mentioned parameters, each selected factor presented in Figure 14 corresponds to one main question, the answer to which allows researchers to determine the degree of satisfaction with a separate factor [8,9]. During the survey, employees and students express their agreement or disagreement with the proposed statements using a six-point rating scale (strongly disagree, disagree, rather disagree, rather agree, agree, completely agree.). Depending on the answers to the proposed statements, a student or a research and teaching staff (professors) is 
considered either engaged or unengaged. The level of engagement of students and research and teaching staff at the university is the percentage of engaged who have passed through the investigation in the total amount of respondents finalized the questionnaire, which is measured in the range from $0 \%$ to $100 \%$.

The visual characteristics of the sample of the study conducted at the NRNU MEPhI are represented in Figure 15.

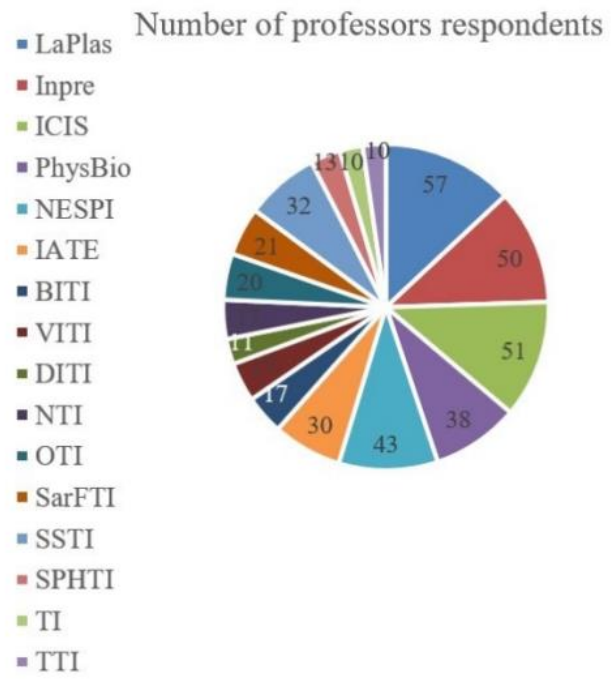

Number of students respondents

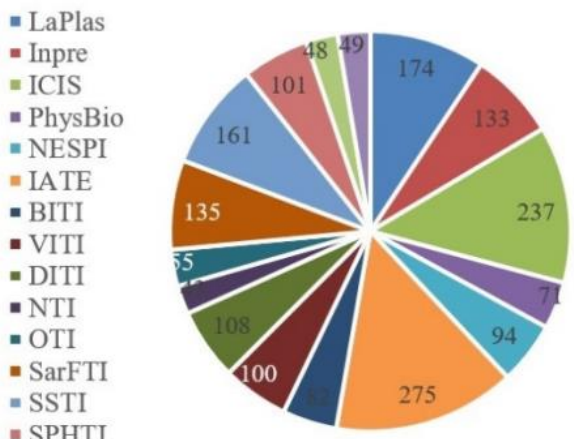

Fig 15. Visual representation of the results of the study of the engagement of students and research and teaching staff of the University

The results of the University engagement investigation for different categories of respondents, as well as a comparison of measurements with well-known benchmarks performed on the example of enterprises included in the contour of the State Atomic Energy Corporation Rosatom, are presented in Figure 16.

As it is shown in the figure, some parameters need additional comprehensive analysis in order to provide corrective measures to maintain more stable values and achieve higher results. Thus, the improving impacts should be focused on the following parameters: remuneration and recognition, infrastructure, career opportunities, training and development. The achieved high values of the parameters must be maintained within the framework of the content of the activity and independence.

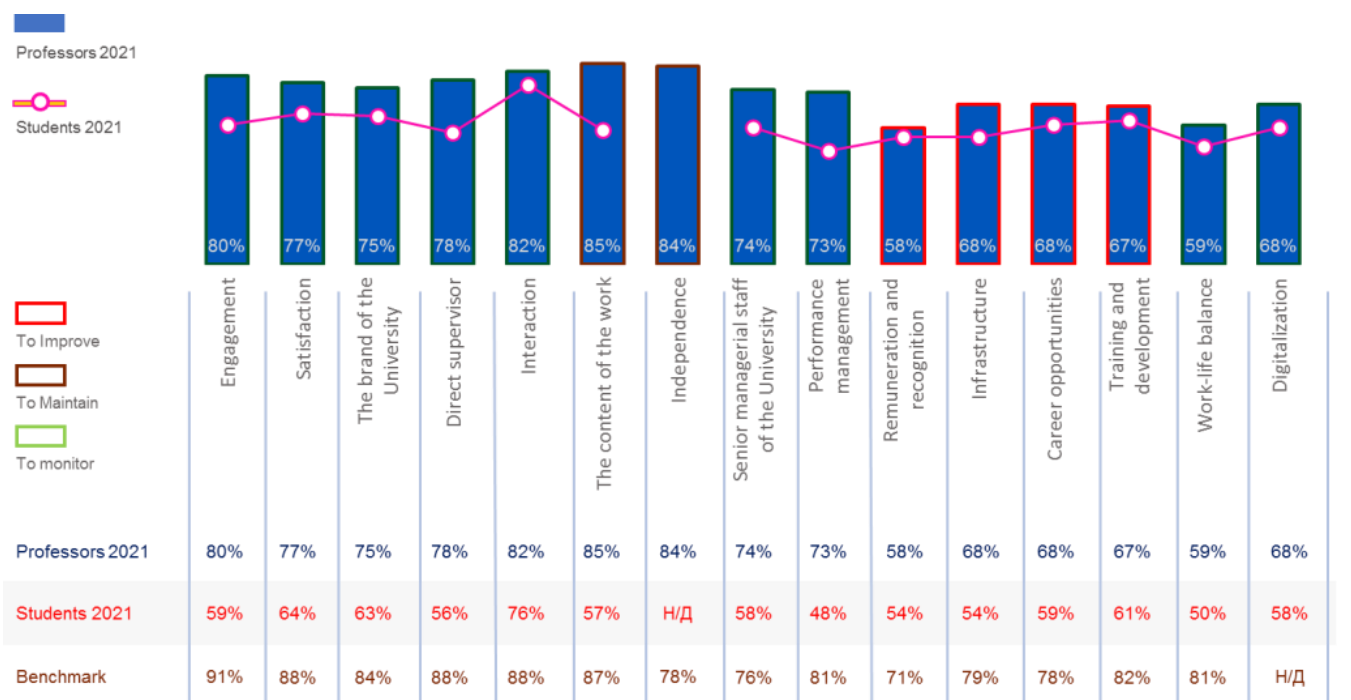

Fig.16. Visual model of the factors of engagement research at the University 
The study of engagement allows researcher to identify key areas of growth and development at the University and develop further steps to improve competitiveness based on the opinion of respondents expressing attitudes to a number of parameters and factors of the organization of a joint communication environment, the conditions for the functioning of information services, team interactions.

So-called 360-degree assessment allows researcher to comprehensively characterize the evaluated employee from various points or focuses of view, including the direct supervisor, subordinates, colleagues, partners, as well as other potential stakeholders.

Within the framework of the 360-degree assessment technology, a set of questionnaire surveys is implemented for an employee of the organization performing managerial functions, the purpose of which is to find out the opinion of the stakeholders about the evaluated parameters. The stakeholders of the assessment are colleagues, the environmentcontractors with whom the employee interacts, subordinates, the employee's manager, as well as the self-assessment of their qualities is carried out by the evaluated person himself. The visual model of the 360-degree assessment is built on the principle of a petal diagram, along the axes of which the level of detected development is postponed in accordance with a scale from 0 to 4 units. The accepted conditional target level is the value 3.5 with which the obtained evaluation results are visually compared.

The represented visual profile of the survey is used in the future to build a development model and form an individual employee plan $[7,8]$.

The list of 360 degree assessment questions includes the following: 1. Do you agree that the evaluated person gives useful feedback and is open to criticism from others? 2. Do you agree that the evaluated person motivates others and is always a good example for them? 3 . How much in-depth analysis do you need to make decisions? 4. How easy is it for you to make independent decisions? 5. Are you always ready to take responsibility for your decisions?

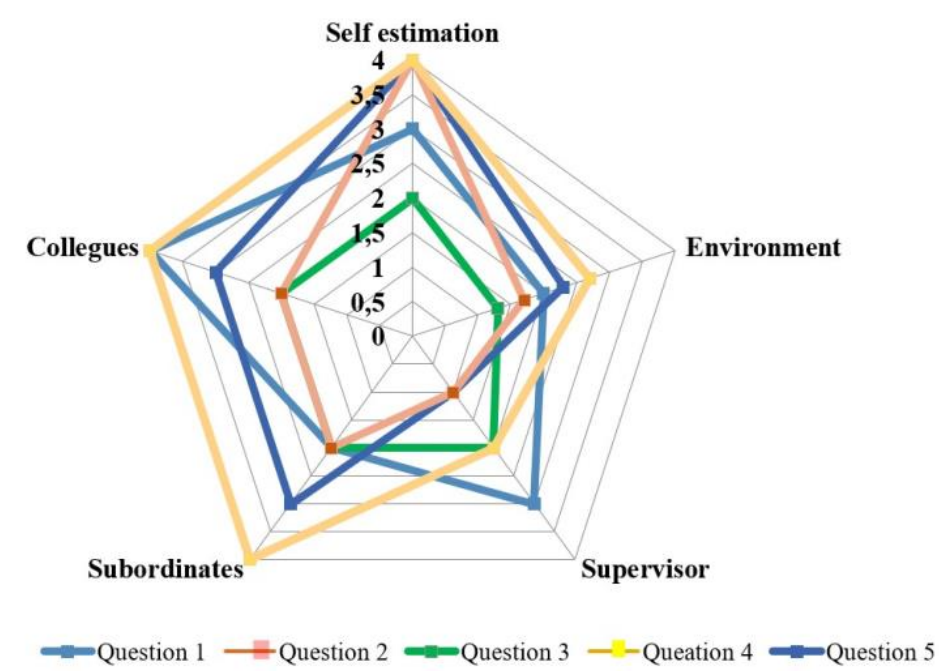

Fig. 16. A visual model in the format of a petal diagram that reflects the results of an employee's assessment by colleagues, the environment, performers interacting with him or external contractors, the manager, subordinates

The final employee's potential assessment is formed on the basis of the provided complex of engagement studies, 360-degree assessment, assessment of the employee by competencies, taking into account the achieved level of horizontal interaction of the department, based on the results of the evaluation of performance indicators.

The potential assessment $[7,11]$ allows managers to distribute employees according to the levels of the achieved results and then form steps for further development of the necessary set of competencies in the organization. Usually, employee's competencies assessments, as well 
as on the achieved value of the indicator of key performance indicators map, are used as evaluation indicators.

The final assessment of the employee's potential is formed on the basis of the provided complex of engagement studies, 360-degree assessment, assessment of the employee by competencies, taking into consideration the achieved level of horizontal interaction between the organizational units, based on the results of the evaluation of performance indicators.

To determine the levels, a visual model of the employee's potential assessment matrix is used, which is applied to correlate the level of competence development and the achieved values of the key performance indicators reflected in the employee's KPI map. A visual model of the potential assessment matrix and the ratio of numerical evaluation results are presented in Figure 17.
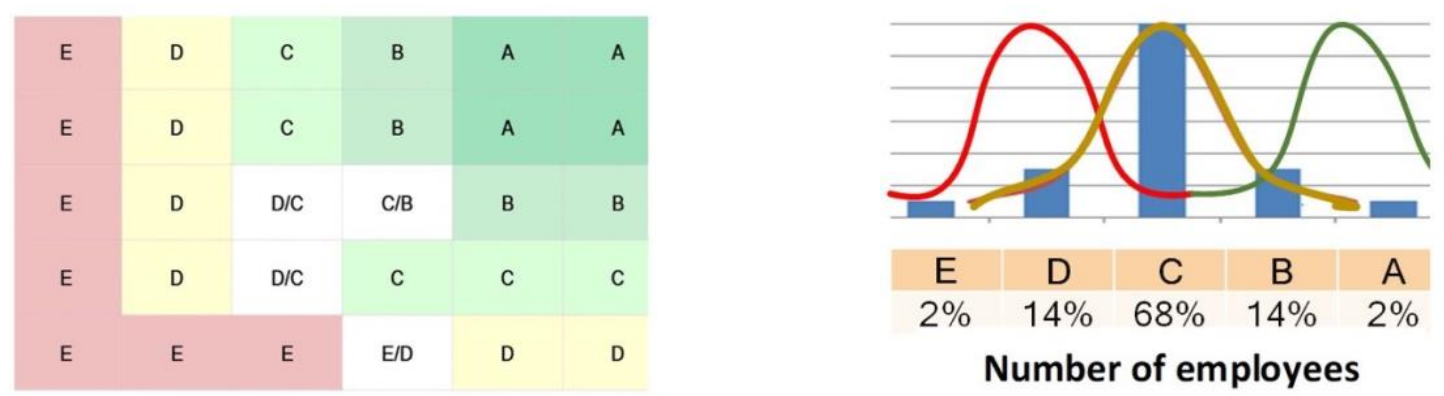

Fig 17. Potential evaluation matrix and evaluation criteria based on the normal distribution function

As part of the integrated capacity assessment procedures, it should be taken into consideration that the number of ratings received by employees is distributed in accordance with the law of normal distribution, the largest number of ratings belongs to the range with a rating of $\mathrm{C}$, the numerical assessment of this group is $68 \%$ of the total number of organization employees and is the largest group, while the number of the highest ratings with A level is only $2 \%$, as well as the number of the worst ratings of $\mathrm{E}$.

As a result of the assessment of the employee's potential, the next career step is planned. Figure 18 represents a visual three-level model of the University's personnel reserve, taking into consideration the characteristics and parameters of the transitions between levels.

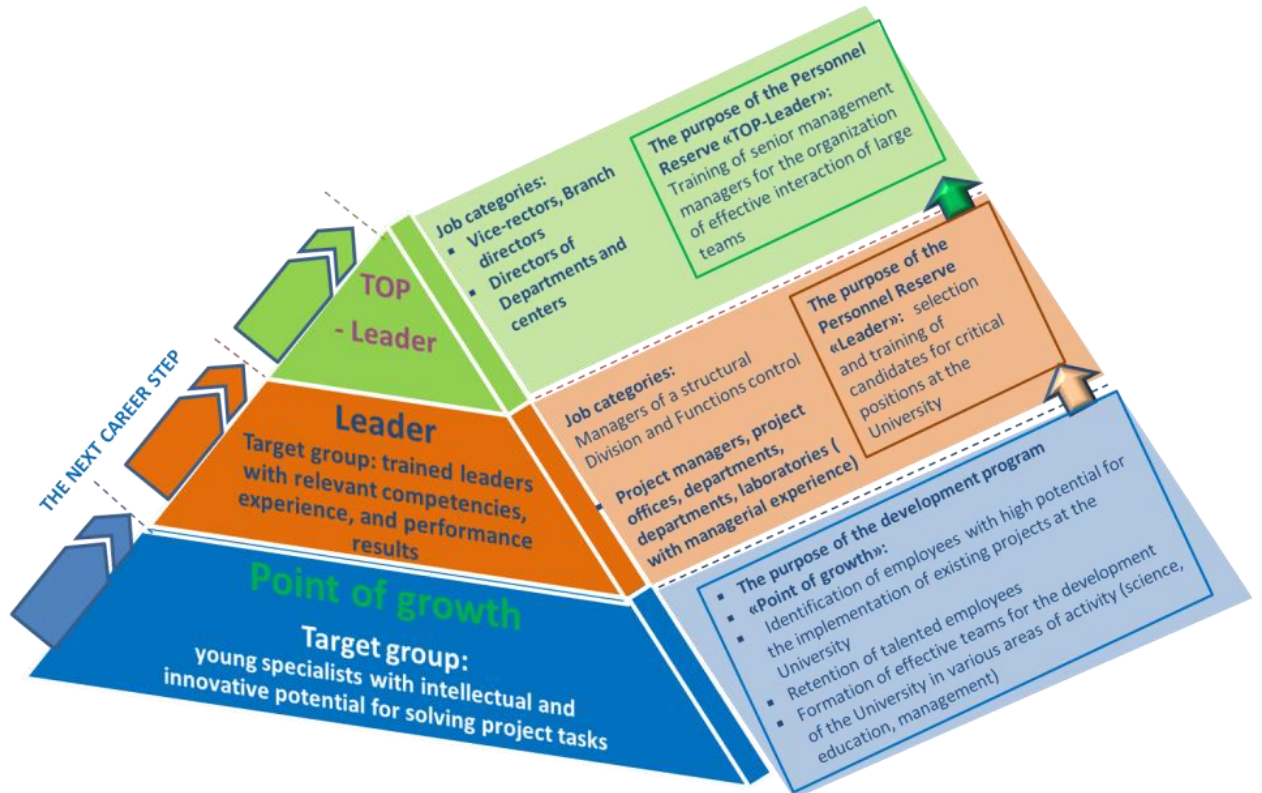

Fig. 18. Visual model of the University's personnel reserve [6] 
During the transition between the levels, the formation of an individual development plan is implemented, focused on the development of the necessary set of competencies, knowledge, skills and abilities used by the employee in their daily work $[6,7,8,11]$.

Figure 19 shows a geometric model of the structure of the individual development plan of the University staff, reflecting a set of activities and forms of work for further career growth and identification of areas of improvement.

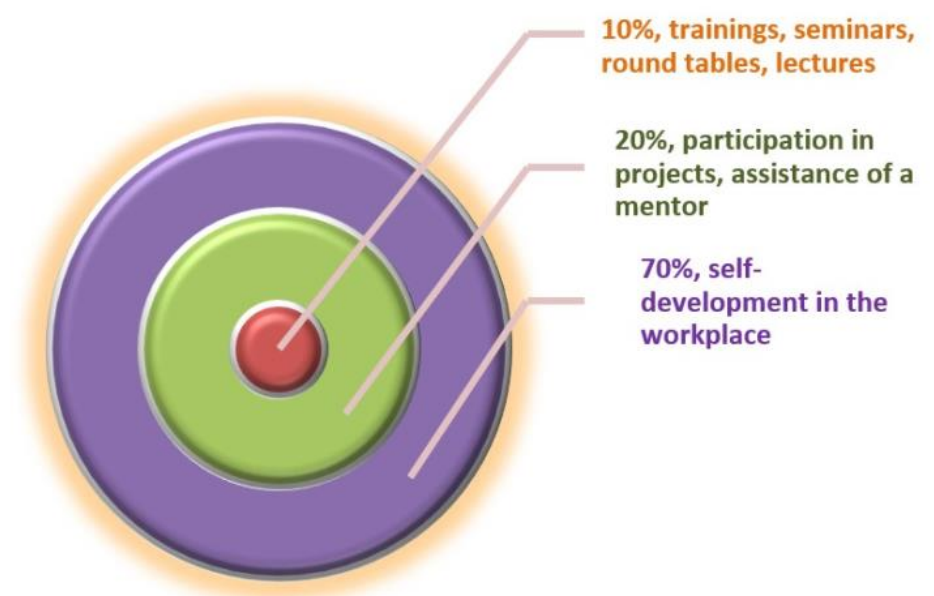

Fig. 19. Visual model of the structure of an individual employee development plan

The presented set of visual models and a tool for supporting the visualization of the indicator system as a business analytics platform allows researchers to systematically display the processes of performance management, as well as the formation and development of the University's human resources potential.

\section{Conclusion}

The application of visual analytics methods is a key means and method of informed management decision-making in the field of control of performance management processes, as well as the development of the personnel potential of an educational organization [5].

The set of visual models proposed, developed and used by the authors in practice, is based on the application of the experience of high-tech companies and enterprises of knowledge-intensive sectors of the economy. The development of a system of visual models for evaluating the effectiveness of activities and personnel potential was carried out using the methods of implementing research in the field of personnel management used in Rosatom State Corporation. In the field of engagement management and visualization of research parameters, the approach used by the international company Kincentric is applied [9, 10].

In the University environment, software tools are used to automate and visualize the processes of performance management

In the University environment, in order to automate and visualize the processes of performance management, the KPI Monitor Analyzer software tool is used [13,14,15], which allows to create an integrated information model that effectively applies the visual analytics tools to display the main decision-making processes and reflect the dynamics of changes in the formed system of indicators of development and increasing the competitiveness of the University.

The formation of a tree of strategic goals allows investigators to display the planned development vectors in the form of a visual model and present the future state of the University in the format of displaying a system of indicators, defining a list of responsible performers, correlating performance indicators with the existing organizational structure of the University, formulating development perspectives and entering new markets for educational services and promising scientific research [11]. 
The system of visual models of indicators serves as the basis for the implementation of a set of changes in the organization, contributing to the increase of competitiveness and the development of the personnel potential of the organization as an integral tool for supporting implemented initiatives and activities in selected areas and spheres of development.

The set of activities carried out by the authors in the sphere of information and analytical tools creation in the field of automation of performance management processes $[5,16]$, the development of human resources and the formation of a complex of visual models can be used in various organizations of the educational sphere of activity on the basis of a single methodological approach.

The portability of the proposed solutions lies in the possibility of developing models of key indicators in accordance with the necessity of the educational organization, setting up mechanisms for visualizing performance indicators, setting up an information base and reference data, through integration of corporate storage and flexible methods for configuring a software application $[5,16]$.

According to the authors opinion, the main task in constructing a system of visual models based on specialized information tools [3,4] is to develop a well-thought-out methodology for forming a system of performance indicators based on the tree of goals of an educational organization, experience in operational and financial activities, activities in the field of personnel management $[6,7]$.

The effect associated with the introduction of a system of visual models is aimed at reducing the time of decision-making on the formation of a complex of educational services, the development or improvement of the research agenda in the face of continuous changes and new challenges, allowing to increase the competitiveness of the University, moving towards digitalization and the creation of information services, organizing a modern comfortable innovative environment, a new human-centered corporate culture [12, 13, 14], turning the University into an educational corporation that assesses and analyzes the future trends of its development at each stage.

\section{References}

1. Pilyugin V. V. Computer geometry and visualization. M. Moscow: MEPhI, 2005. p. 120

2. Kolychev V.D. Specificity of the product's life-cycle management models / V.D. Kolychev, V.P. Rumyantsev // Non-ferrous metals, 2014, vol. 2. pp pp. 3-7.

3. Kolychev V. D. Sistema visualnykh modelov upravleniya proektami / V. D. Kolychev, V. P. Rumyantsev // Nauchnaya visualizatsiya, 2014. 3(6). Pp. 14-54.

4. Leonova N. M., Kolychev V. D., Modyaev A.D. Visualization of product life cycle processes in the unified information space of the enterprise on the basis of project management methods. Vol. 8, no. 5. 2016. pp. 26-40

5. Lvovich I.Y., Lvovich Y.E., Preobrazhenskiy A.P., Preobrazhenskiy Y.P., Choporov O.N. Modeling of Control Process of Industrial Organizations Based on Rating Approach. Modeling, Optimization and Information Technology. 2020; 8(3). Available from: https://moit.vivt.ru/wpcontent/uploads/2020/o8/LvovichSoavtors_3_20_1.pdf DOI: 10.26102/2310-6018/2020.30.3.026 (In Russ).

6. Kolychev V. D., Belkin I. O., Udovidchenko R. S. Specificity and resultativeness of programs for the development of managerial competencies of the personnel reserve. 2019. No. 11 (28). pp. 134-143.

7. Moroz A. S., Sharapova N. V. Personnel performance management. Current issues of the modern economy. 2018. No. 2. From 9-13

8. Shtanko A.N., Kulik S.D., Kondakov A.A. Effective scientific personnel training in the field of modern computer technologies for the implementation of advanced research projects of the Megascience class. Journal of Physics: Conference Series. Volume 1685, Issue 120 November 2020 2nd Conference on Personnel Training and Legal Support for the Implementation of Research Projects of the MegaScience Class, 25 June 2020 
9. Kincentric Employee Engagement Model (Aon Hewitt). [Electronic resource]. URL:https://axes.ru/articles/model-vovlechennosti-sotrudnikov-aon-hewitt/ (accessed 31.05.2021).

10. Global Trends in Engagement: Annual Review 2020. Internet link (https://axes.ru/articles/mirovye-trendy-v-vovlechennosti-ezhegodnyy-obzor-2020 / accessed 25.05.2021) Source: "2020 Trends in Global Employee Engagement" by Christopher Adair, Ph. D., July 2020

11. Kulik S.,Tkachenko K. Effective strategy for competences forming. 2016 3rd International Conference on Digital Information Processing, Data Mining, and Wireless Communications, DIPDMWC 2016. Pages 239 - 2442

12. Kolesnikov A.M., Khrapovitskaya E. M. The effectiveness of corporate culture and its impact on the organization's activities. Economic vector. 2019. No. 3 (18) pp. 24-28

13. KPI MONITOR Analyzer in the Project "Development of the National Research Nuclear University". [Electronic resource]. URL: http://kpimonitor.ru/infocenter/news/niyumifi-monitoring (accessed 08.06.2021).

14. Denisova M. N., Zheleznov O. V. Development of a methodology for monitoring key performance indicators of business processes of an aircraft manufacturing enterprise using KPI Monitor. Proceedings of the Samara Scientific Center of the Russian Academy of Sciences. 2013. Vol. 15. No. 4(3). pp. 675-683

15. KPI MONITOR Analyzer, Limited liability corporation ProfITProject. [Electronic resource]. URL: http://kpi-monitor.ru/about/vendor-info (accessed 30.06.2021).

16. Kolychev V.D., Shebotinov A.A. Application of Business Intelligence instrumental tools for visualization of key performance indicators of an enterprise in telecommunications. // Nauchnaya visualizatsiya. 2019. No. 1(11). Pages. 20-37. 